\title{
Leaks can dramatically decrease FiO2 on home ventilators: a bench study
}

\author{
Philippe Goutorbe*, Erwan Daranda, Yves Asencio, Pierre Esnault, Bertrand Prunet, Julien Bordes, Bruno Palmier \\ and Eric Meaudre
}

\begin{abstract}
Background: Long term oxygen therapy improves survival in hypoxemic patients with chronic obstructive pulmonary disease (COPD). Because pressure support ventilation with a home care ventilator is largely unsupervised, there is considerable risk of leakage occurring, which could affect delivered $\mathrm{FiO}_{2}$. We have therefore conducted a bench study in order to measure the effect of different levels of $\mathrm{O}_{2}$ supply and degrees of leakage on delivered $\mathrm{FiO}_{2}$. Ventilator tested: Legendair ${ }^{\circledR}$ (Airox ${ }^{\mathrm{TM}}, \mathrm{Pau}$, France). Thirty-six measures were performed in each four ventilators with zero, 5 and 10 l.min-1 leakage and 1,2,4 and 8 I 02 flow.
\end{abstract}

Findings: $\mathrm{FiO}_{2}$ decreased significantly with 5 I.min-1 leakage for all $\mathrm{O} 2$ flow rates, and with 10 I.min-1 at 4 and 8 I. min-1 O2.

Conclusion: During application of NIV on home ventilators, leakage can dramatically decrease inspired FiO2 making it less effective. It is important to know the FiO2 dispensed when NIV is used for COPD at home. We would encourage industry to develop methods for $\mathrm{FiO} 2$ regulation Chronic use of NIV for COPD with controlled FiO2 or $\mathrm{SpO} 2$ requires further studys.

Keywords: NIV, Leaks, Home ventilation, COPD, FiO2

\section{Background}

Long-term oxygen therapy (LTOT) improves survival in hypoxemic patients with chronic obstructive pulmonary disease (COPD) [1,2]. The minimum recommended duration of $\mathrm{O}_{2}$ therapy is 15 hours per day. Non-invasive ventilation (NIV) is now recommended for acute on chronic COPD respiratory distress, whereas its chronic use is more controversial [3,4]. Nocturnal non-invasive ventilation (NIV) improves quality of life and blood gas status, with fewer intensive care admissions, although survival is not affected $[5,6]$. Most home care ventilators deliver pressure support via a turbine and a constant normobaric $\mathrm{O}_{2}$ supply $[7,8]$. The $\mathrm{O}_{2}$ source is liquid $\mathrm{O}_{2}$ or from extractors. We hypothesized that, whereas ICU ventilators deliver the set Fi02 (hyperbaric 02 witch permits variable $\mathrm{O} 2$ supply), with pressure support NIV, leakage around the mask could influence the received $\mathrm{FiO} 2$. Indeed leaks are well compensated by modern's

\footnotetext{
* Correspondence: goutorbephil@live.fr

Emergency, Anesthesia and ICU Departement, Military Teaching Hospital Sainte Anne, Boulevard Sainte Anne, Toulon 83000, France
}

home ventilators by delivering higher flows, using an additional volume taken from the room air. Under constant $\mathrm{O} 2$ supply FiO2 should decrease. We therefore analysed the variation of delivered $\mathrm{FiO}_{2}$ in pressure support ventilation with a home care ventilator under different levels of $\mathrm{O}_{2}$ supply and leakage in a bench study.

\section{Material and method}

Experimental bench study

A Legendair ${ }^{\circledR}$ (Airox ${ }^{\mathrm{TM}}$, Pau, France) ventilator was set to give pressure support ventilation (PSV) with an expiratory pressure (PE) of $5 \mathrm{cmH} 2 \mathrm{O}$ and inspiratoty pressure (PI) of $15 \mathrm{cmH} 2 \mathrm{O}$. A standard single circuit with valve was used to connect the ventilator with the test chamber. In place of the mask we used a 'leaks valve', which could allow 0,5 or $101 . \mathrm{min}^{-1}$ leakage. The level of leakage was calibrated during a continuous airway pressure 10 $\mathrm{cmH} 2 \mathrm{O}$, with two pneumotachographs one before and one after the valve (Fleisch 6V, Lausanne, Switzerland). Signals were digitized by an analogic/digital system (MP150, Biopac Systems, Goleta, CA) with modules (DA 100V 1000z, Biopac System). The O2 supply was 
set on the ventilator and flow was measured by a FlowAnalyser PF-300 (Imtmedical, Switzerland).

The test lung was the two-chamber Michigan test lung (Training/test lung-TTL ${ }^{\circledR}$, adult infant lung simulator; Michigan Instrument ${ }^{\mathrm{Tm}}$, Grand Rapids, MI), which has been described in detail in previous studies $[9,10]$; the infant lung was used as driving chamber and linked with the pressurized (test) chamber. The driving ventilator Puritan Bennet (PB) 840 (set in controlled ventilation) produces a negative pressure in the adult chamber, which is recognized as an inspiratory effort by the test ventilator. The characteristics of the test chamber were that of a parabolic airway resistor of $20-\mathrm{cmH} 2 \mathrm{O} \mathrm{l^{-1 }}$. - $^{-1}$ (Pneuflo ${ }^{\circledR}$ Airway resistor; Michigan Instrument ${ }^{\mathrm{Tm}}$, Grand Rapids, MI) and compliance was set at $60 \mathrm{ml} / \mathrm{cmH} 2 \mathrm{O}$. The respiratory rate of the driving ventilator was set to 15 per minute. The oxygen fraction in the test chamber was measured with a Puritan Bennet ${ }^{\mathrm{TM}}$ O2 Monitor 7820. We tested four flows of oxygen supply $(1,2,4$ and 8 liters/minute) and $\mathrm{FiO}_{2}$ for each with a 0,5 and 10 liter/ minute leak. The test chamber $\mathrm{FiO}_{2}$ was noted three times for each condition (Figure 1).

The Kruskal-Walis test was used to compare all variables and the post hoc Steel test if significance was found. All data are presented as group median [25-75]. Statistical analysis was performed with JMP 9.3 (SAS Institute, Cary, NC). Statistical significance was defined as $p<0.05$.

\section{Findings}

Four different ventilators were tested three times each, with 12 measurements of $\mathrm{FiO} 2$ for each condition of oxygen supply and leakage. Leakage significantly affected $\mathrm{FiO} 2$ for all $\mathrm{O} 2$ supply between no leak and 5 liters per minute of leaks. FiO2 decreased significantly with 10 liters per minute of leaks only for 4 and 8 liters O2 supply (Table 1 and Figure 2).

\section{Discussion}

The bench study confirms our hypothesis in six cases of eight; FiO2 decreases with all O2 flows with 5 liters per minute leaks and with 4 and 8 liters $\mathrm{O} 2$ supply with 10 liters per minute of leaks. We are not able to explain why in several conditions $\mathrm{FiO} 2$ increased with 10 liters per minute of leaks. We assume that it would be possible venturi effect with increased $\mathrm{O} 2$ flow but this one was continuously measured by a FlowAnalyser PF-300 (Imtmedical, Switzerland) and it was constant.

The Nocturnal Oxygen Therapy Trial (NOTT) and the Medical Research Council study, using similar inclusion criteria, demonstrated the beneficial effects of LTOT on survival in subjects with COPD and severe resting hypoxemia. The median survival in those using $\mathrm{O} 2$ for 15 hours/day was approximately twice that of those receiving no $\mathrm{O} 2[1,2]$. The use NIV in acute exacerbation of COPD is now recommended. Two RCTs of long term NIV for respiratory failure failed to demonstrate any effect

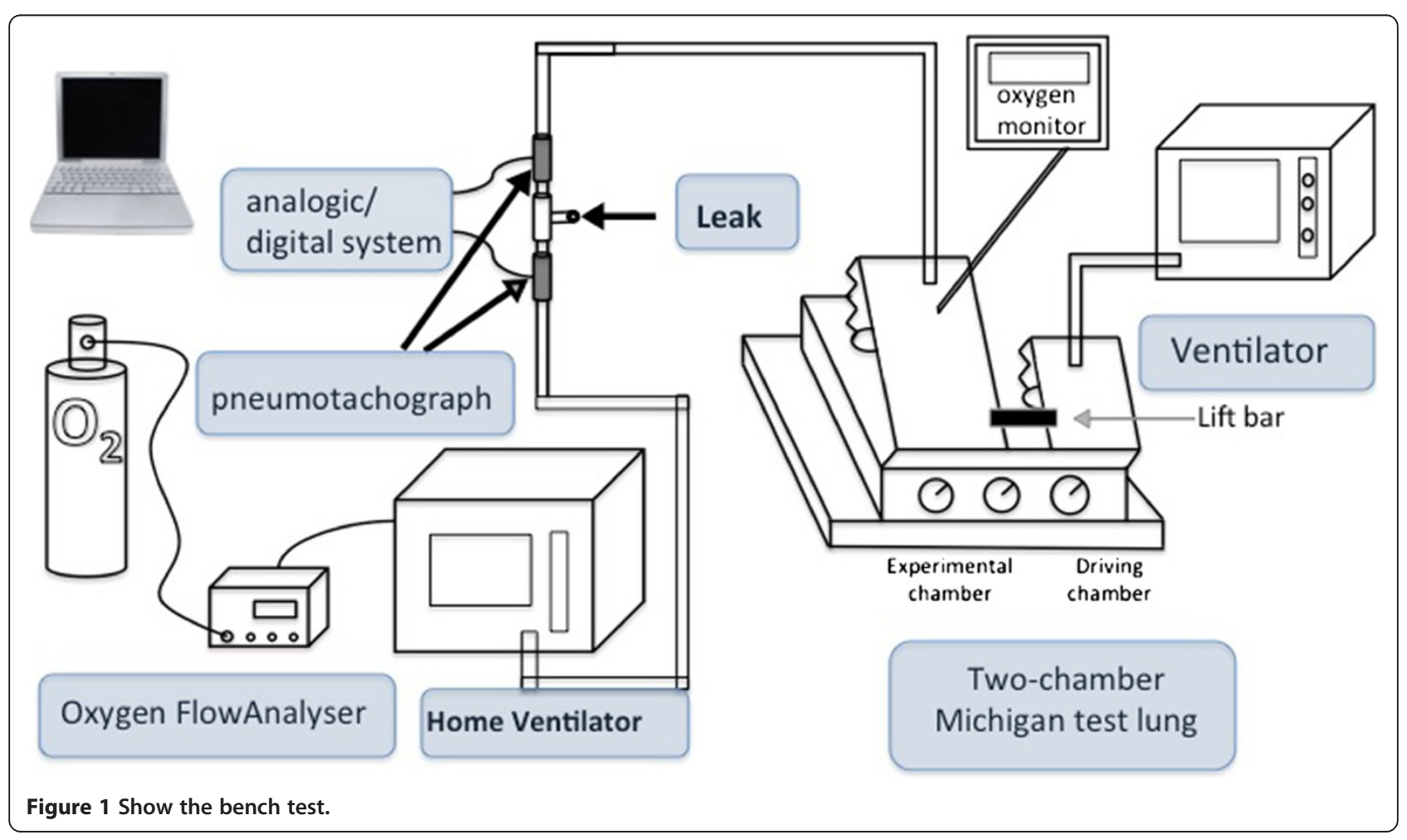




\begin{tabular}{llcrr}
\hline & & \multicolumn{3}{c}{ Leakage (liters per minute) } \\
\cline { 3 - 4 } & & $\mathbf{0}$ & $\mathbf{5}$ & $\mathbf{1 0}$ \\
$\mathbf{n}=\mathbf{n}=\mathbf{1 2}$ & $\mathbf{1 2}$ & $25.1[23.8-25.1]$ \\
Oxygen supply & $1 \mathrm{l} / \mathrm{min}$ & $24.2[23.7-24.4]$ & $23.6[23.2-23.9]^{*}$ & $29.3[27.4-29.6]$ \\
& $2 \mathrm{I} / \mathrm{min}$ & $28.6[28.5-28.8]$ & $27.0[26.1-27.6]^{*}$ & $36.6[34.5-38.0]^{*}$ \\
& $4 \mathrm{I} / \mathrm{min}$ & $39.0[38.0-40.0]$ & $34.0[33.0-34.6]+$ & $49.5[47.1-51.6]+$ \\
\hline
\end{tabular}

$\dagger p<0.0001 ;{ }^{*} p<0.05$ compared to control group (no leakage).

on mortality, although quality of life was improved and there were fewer hospital admissions. $\mathrm{SPO}_{2}$ at home was not reported [5,6].

Although some studies show no improvement in mortality $[5,6,11]$, the physiological basis for NIV is clear; it relaxes the inspiratory muscles. External PEEP should counteract intrinsic PEEP [12], and VA/Q ratios may be improved [13]. However, leakage caused by movement of the mask is common. Opening the mouth, and poor fit to the face associated with weight loss, leads to leakage, especially at night [14]. Fortunately, many home ventilators now have well-developed software to detect and compensate for leaks from room air, and can compensate for leakage of about $301 \cdot \mathrm{min}^{-1}[15]$. Nevertheless, leaks can decrease the delivered $\mathrm{FiO}_{2}$ because the $\mathrm{O}_{2}$ supply is constant, as demonstrated here. NIV failure to improve surviving in chronic COPD may be due to this.

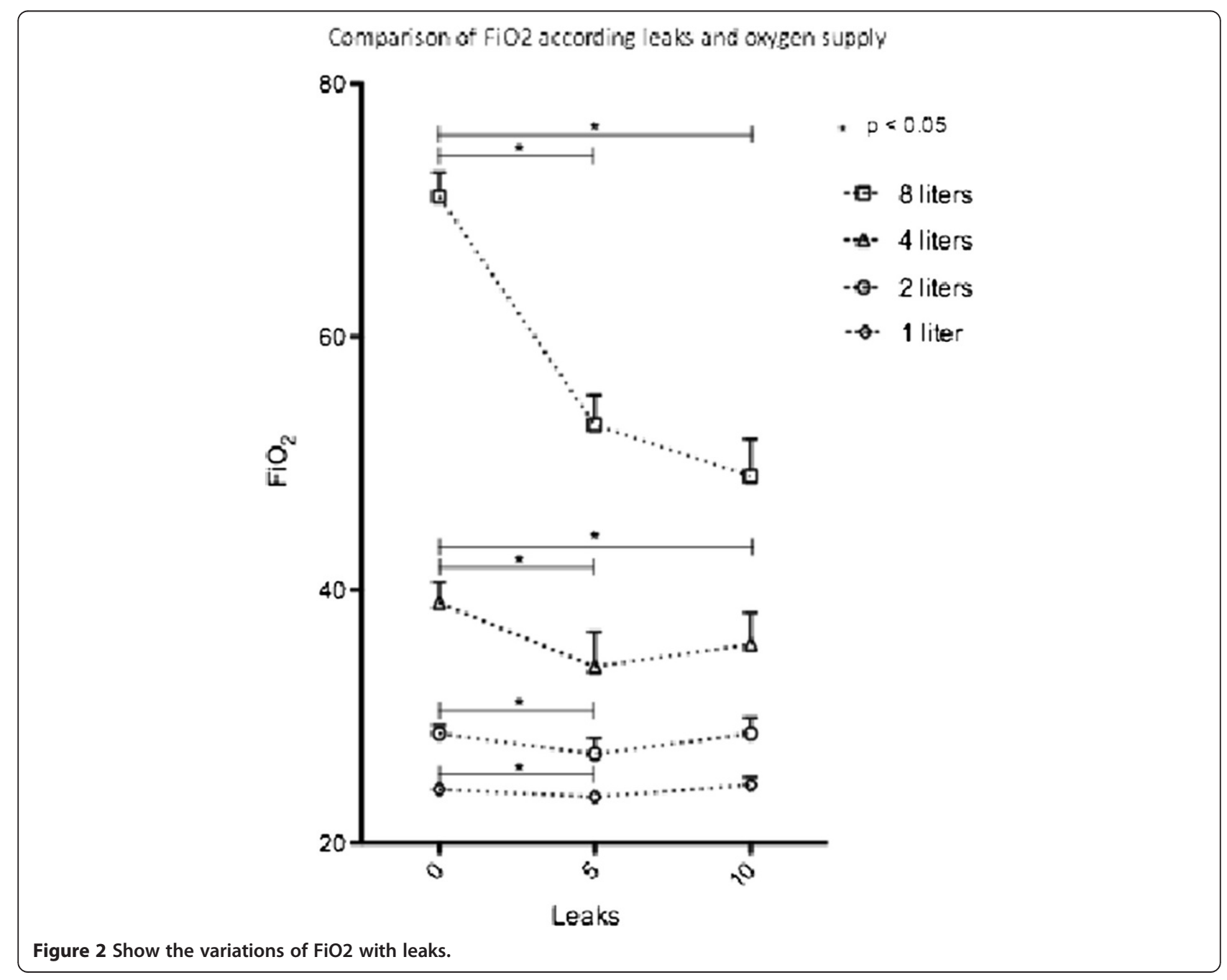


There are no studies of the delivered FiO2 in NIV, the value of which is increased by oxygen supplementation with home ventilators. Thys and Schwartz showed the influence of site oxygen delivery on $\mathrm{FiO} 2[16,17]$. Although in several home ventilators using a liquid $\mathrm{O}_{2}$ source or an $\mathrm{O}_{2}$ extractor, $\mathrm{FiO}_{2}$ can be monitored but it is not possible to set. Unfortunately regulation of $\mathrm{FiO}_{2}$ with home ventilators is not yet available. Our study is the first to focus on the affect of leakage on $\mathrm{FiO}_{2}$ during NIV with home ventilators, although such effects have been previously shown with ICU ventilators [18]. In several conditions $\mathrm{FiO}_{2}$ can vary by up to $30 \%$. With the $\mathrm{O} 2$ supply of 81 . $\min ^{-1}$ we found a decrease in $\mathrm{FiO}_{2}$ from 70 to $50 \%$ with a leakage of $101 . \mathrm{min}^{-1}$.

NIV offers an excellent treatment for chronic respiratory insufficiency, but in the home there is no control of leaks or measurement of $\mathrm{SPO}_{2}$. In a recent meta-analyse Chen et al. point out that with an inspiratory positive airway pressure (IPAP) greater or equal than $14 \mathrm{cmH} 2 \mathrm{O}$ the $\mathrm{PaO} 2$ decreased [19]; increasing of leaks with high airway pressure should explain that. With increasing leakage, $\mathrm{FiO}_{2}$ decreases, and hypoxemia ensues leading to an increase of minute respiratory intake which in turn results in aspirating room air; if the $\mathrm{O}_{2}$ supply is constant then $\mathrm{FiO}_{2}$ decreases again leading a vicious circle of hypoxemia. This may explain the poor results of treating respiratory failure with NIV in the home.

The $\mathrm{O}_{2}$ supply can be triggered by the patient's $\mathrm{SpO}_{2}$ or the ventilator $\mathrm{FiO}_{2}$. The former is more relevant clinically; the latter is more easily measured. The cost of measuring $\mathrm{FiO}_{2}$ is about 1000 Euros; $\mathrm{SpO}_{2}$ is less expensive but the measurement is subject to artefacts.

The design (bench test) limits the impact of the findings. On the over hand we underestimated the leaks, which could reach 30 liters per minute; the $\mathrm{FiO} 2$ decrease may be greater in clinical conditions.

We purpose to adjunct and $\mathrm{O} 2$ turbine witch should adjust $\mathrm{O} 2$ flow supply to a $\mathrm{SpO} 2$ objective.

New home NIV chronic use in COPD study's should be conducted with this $\mathrm{O} 2$ flow control.

We propose to add a dedicated $\mathrm{O} 2$ turbine allowing automated $\mathrm{O} 2$ flow adjustment in order to achieve a predefined $\mathrm{SpO} 2$.

Thereafter, studies will be mandatory to evaluate effects of this automated $\mathrm{O} 2$ flow supply on COPD prognosis.

\section{Conclusion}

This lung model study demonstrates that during application of NIV on home ventilators, leakage can dramatically decrease FiO2 making it less effective. As consequence, it is essential to know the $\mathrm{FiO} 2$ dispensed during NIV at home. Further research should explore the role of the O2 flow control during application of NIV in chronic hypercapnic COPD patients.
We hope that industry can address the problems we have highlighted in this study.

\section{Abbreviations}

COPD: Chronicle obstructive pulmonary disease; FiO2: Inspired fraction of oxygen; IPAP: Inspiratory positive airway pressure; LTOT: Long term oxygen therapy; O2: Oxygen; NIV: Non invasive ventilation; NOTT: Nocturnal Oxygen Therapy Trial; PEEP: Positive end expiratory pressure; VA/Q: Ratio: ventilation perfusion ratio.

\section{Competing interest}

The authors declare no competing interest.

\section{Authors' contributions}

GP drove the research and write the article, AY made the statistical analysis; and all the authors contributed to measurements. All authors read and approved the final manuscript.

Received: 6 May 2013 Accepted: 18 July 2013

Published: 21 July 2013

\section{References}

1. Continuous or Nocturnal Oxygen Therapy in Hypoxemic Chronic Obstructive Lung Disease [Internet] annals.org. ; 2012. 2012 [cited 2012 Feb 8]. Available from: http://www.annals.org/content/93/3/391.abstract?sid=79927bd3-e7f24273-baab-19b98e3d4991.

2. Council M: Long term domiciliary oxygen therapy in chronic hypoxic cor pulmonale complicating chronic bronchitis and emphysema: Report of the Medical Research Council Working Party. Lancet 1981, 1(8222):681-686.

3. Rossi A: Noninvasive ventilation has not been shown to be ineffective in stable COPD. Am J Respir Crit Care Med 2000, 161(3 Pt 1):688-689.

4. Hill NS: Noninvasive ventilation has been shown to be ineffective in stable COPD. Am J Respir Crit Care Med 2000, 161(3):689-691.

5. Casanova C, Celli BR, Tost L, Soriano E, Abreu J, Velasco V, et al: Long-term controlled trial of nocturnal nasal positive pressure ventilation in patients with severe COPD. Chest 2000, 118(6):1582-1590.

6. Clini E, Sturani C, Rossi A, Viaggi S, Corrado A, Donner CF, Ambrosino N, Rehabilitation and Chronic Care Study Group, Italian Association of Hospital Pulmonologists (AIPO): The italian multicentre study on noninvasive ventilation in chronic obstructive pulmonary diseases patients. Eur Respir J 2002, 20(3):529-38. Erratum in: Eur Respir J. 2002 Dec;20(6):1617.

7. Cuvelier A, Molano LC, Muir JF: Domiciliary ventilation in patients with COPD. Rev Mal Respir 2005, 22(4):615-33.

8. Lloyd-Owen SJ, Donaldson GC, Ambrosino N, Escarabill J, Farre R, Fauroux B, et al: Patterns of home mechanical ventilation use in Europe: results from the Eurovent survey. Eur Respir J 2005, 25(6):1025-1031.

9. Tassaux D, Strasser S, Fonseca S, Dalmas E, Jolliet P: Comparative bench study of triggering, pressurization, and cycling between the home ventilator VPAP II and three ICU ventilators. Intensive Care Med 2002, 28(9):1254-1261.

10. Richard J-C, Carlucci A, Breton L, Langlais N, Jaber S, Maggiore S, et al: Bench testing of pressure support ventilation with three different generations of ventilators. Intensive Care Med 2002, 28(8):1049-1057.

11. Kolodziej MA, Jensen L, Rowe B, Sin D: Systematic review of noninvasive positive pressure ventilation in severe stable COPD. Eur Respir J 2007, 30(2):293-306.

12. Diaz O, Begin P, Torrealba B, Jover E, Lisboa C: Effects of noninvasive ventilation on lung hyperinflation in stable hypercapnic COPD. Eur Respir J Eur Respiratory Soc 2002, 20(6):1490-1498.

13. Robert $D$, Argaud $L$ : Clinical review: long-term noninvasive ventilation. Crit Care 2007, 11(2):210.

14. Mehta S, Hill NS: Noninvasive ventilation. Am J Respir Crit Care Med Am Thoracic Soc 2001, 163(2):540.

15. Battisti A: Performance Characteristics of 10 Home Mechanical Ventilators in Pressure-Support Mode: A Comparative Bench Study. Chest 2005, 27(5):1784-1792.

16. Schwartz AR, Kacmarek RM, Hess DR: Factors affecting oxygen delivery with bi-level positive airway pressure. Respir Care 2004, 49(3):270-275. 
17. Thys F, Liistro G, Dozin O, Marion E, Rodenstein DO: Determinants of Fi, O2 with oxygen supplementation during noninvasive two-level positive pressure ventilation. Eur Respir J 2002, 19(4):653-657.

18. Miyoshi E: Effects of Gas Leak on Triggering Function, Humidification, and Inspiratory Oxygen Fraction During Noninvasive Positive Airway Pressure Ventilation. Chest 2005, 128(5):3691-3698.

19. Chen H, Liang B-M, Xu Z-B, Tang Y-J, Wang K, Xiao J, et al: Long-term noninvasive positive pressure ventilation in severe stable chronic obstructive pulmonary disease: a meta-analysis. Chin Med J 2011, 124(23):4063-4070.

doi:10.1186/1756-0500-6-282

Cite this article as: Goutorbe et al:: Leaks can dramatically decrease FiO2

on home ventilators: a bench study. BMC Research Notes 2013 6:282.

\section{Submit your next manuscript to BioMed Central and take full advantage of:}

- Convenient online submission

- Thorough peer review

- No space constraints or color figure charges

- Immediate publication on acceptance

- Inclusion in PubMed, CAS, Scopus and Google Scholar

- Research which is freely available for redistribution 